\title{
Características da Carcaça de Novilhos Red Angus Superprecoces Abatidos com Diferentes Pesos
}

\section{Eduardo Castro da Costa1, João Restle ${ }^{2}$, Fabiano Nunes Vaz ${ }^{3}$, Dari Celetino Alves Filho ${ }^{4}$, Regis Augusto L. Carvalho Bernardes ${ }^{5}$, Fernando Kuss ${ }^{6}$}

RESUMO - Foram avaliadas as características quantitativas da carcaça de novilhos Red Angus com idade média inicial de 8 meses e $189 \mathrm{~kg}$, confinados durante 114, 144, 173 e 213 dias até os respectivos pesos de abate (PA) de 340, $370,400 \mathrm{ou} 430 \mathrm{~kg}$, com idade de 12,13, 14 e 15 meses. A dieta alimentar continha uma relação volumoso:concentrado de 56:44, contendo 13,13\% de proteína bruta e 2,7 Mcal de energia digestível/kg MS. O corte serrote, embora tenha aumentado linearmente em peso (91,73; 103,$26 ; 106,20$ e 116,66 kg) frente ao aumento do peso de abate, decresceu linearmente quando expresso em relação ao peso de carcaça fria $(50,55 ; 50,79 ; 50,16 ; \mathrm{e} 48,86 \%)$. A porcentagem do corte costilhar foi a que sofreu maior incremento $(23,36 ; 25,40 ;$ 28,50; e 35\%) com o aumento do peso de abate, acompanhando o aumento na deposição de gordura de cobertura (3,91; 6,16; 6,16; e $9,58 \mathrm{~mm})$. A área do músculo Longissimus dorsi (ALD) aumentou linearmente frente ao aumento do peso de abate $($ ALD = $27,48+0,083 \mathrm{PA})$, enquanto a ALD/100 kg de carcaça fria decresceu linearmente (ALD/100 kg carcaça = 45,14 - 0,0425PA). Foi estimado, por intermédio da equação de regressão, que a espessura de gordura mínima exigida pelos frigoríficos (3 mm) teria sido alcançada com $327 \mathrm{~kg}$ de peso. Considerando o peso de carcaça mínimo de $180 \mathrm{~kg}$, este seria atingido com um peso de abate de $337 \mathrm{~kg}$. Utilizando novilhos da raça Red Angus para produção do superprecoce, o peso de abate não deve ser superior a $400 \mathrm{~kg}$, para não exceder os $6 \mathrm{~mm}$ de gordura de cobertura, evitando o recorte do excesso.

Palavras-chave: composição da carcaça, gordura de cobertura, Longissimus dorsi, peso de abate, rendimento de carcaça

\section{Carcass Traits of Young Red Angus Steers Slaughtered with Different Weights}

ABSTRACT - The carcass quantitative characteristics of feedlot finished Red Angus steers, with initial age of eight months and $189 \mathrm{~kg}$, slaughtered with $340,370,400$ or $430 \mathrm{~kg}(\mathrm{SW})$, were evaluated. The number of days to reach the respective weight was $114,144,173$ and 213 days. The diet contained 13.13\% crude protein, 2.7 Mcal digestible energy/kg DM and a roughage:concentrate ratio of 56:44. Carcass dressing percentage and conformation were not affected by the slaughter weight. The saw cut weight although increasing linearly in weight $(91.73 ; 103.26 ; 106.20$ and $116.66 \mathrm{~kg})$ as the slaughter weight increased, declined linearly when expressed in relation to cold carcass weight. Side cut percentage showed the highest increase (23.36; 25.40; 28.50 and $35 \%)$ as the slaughter weight increased, following the increase of subcutaneous fat thickness (3.91; 6.16; 6.16 and $9.58 \mathrm{~mm}$ ). The Longissimus dorsi muscle (LMA) increased linearly as the slaughter weight increased (LMA $=27.48+0.083 \mathrm{SW})$ while the LMA $/ 100 \mathrm{~kg}$ of cold carcass weight declined linearly (LMA/100 kg carc. $=45.14-0.0425 \mathrm{SW}$ ). According to the regression equation the minimum subcutaneous fat thickness required by the slaughter weights ( $3 \mathrm{~mm})$ would be reached at $327 \mathrm{~kg}$ of live weight. Considering the minimum carcass weight of $180 \mathrm{~kg}$, it would be reached with the slaughter weight of $337 \mathrm{~kg}$. Using Red Angus breed to produce steers to be slaughtered at young age the slaughter weight should not surpass $400 \mathrm{~kg}$, in order to not exceed the $6 \mathrm{~mm}$ of subcutaneous fat thickness, to avoid the carcass trimming for fat excess.

Key Words: carcass composition, carcass dressing, Longissimus dorsi, slaughter weight, subcutaneous fat

\footnotetext{
1 Zootecnista, Aluno do Curso de Mestrado em Zootecnia da UFSM. E.mail:dacostaec@zipmail.com.br

${ }^{2} \mathrm{Eng}^{\circ} \mathrm{Agr}^{\circ}$, PhD, Pesquisador do CNPq, Professor Titular do Departamento de Zootecnia da UFSM, Camobi, Santa Maria, RS, CEP $97105-900$. E.mail:jorestle@ccr.ufsm.br

${ }^{3}$ Zootecnista, MSc, PROGEPEC Consultores Associados LTDA.

${ }^{4} \mathrm{Eng}^{\circ} \mathrm{Agr}^{\circ}, \mathrm{MSc}$, Professor Assistente do Departamento de Zootecnia da UFSM.

${ }^{5}$ Zootecnista, MSc, Professor Assistente do Departamento de Zootecnia da UFSM.

${ }^{6}$ Aluno do curso de Zootecnia - UFSM. Bolsista IC - FAPERGS.
} 


\section{Introdução}

O estudo das características da carcaça tem importância, quando o objetivo é avaliar a qualidade do produto final de um sistema. $\mathrm{O}$ rendimento de carcaça e dos cortes comerciais e o peso de carcaça são medidas de interesse dos frigoríficos na avaliação do valor do produto adquirido e nos custos operacionais, visto que carcaças com pesos diferentes demandam a mesma mão-de-obra e tempo de processamento. Ao abater animais com maiores pesos, podem ocorrer mudanças no desempenho (Barber et al., 1981a; Restle et al., 1997a) e nas características de carcaça (Barber et al., 1981b; Restle et al., 1997b). Portanto, o peso de abate tem grande importância no confinamento, por alterar custos e qualidade do produto final.

A produção de animais jovens, também denominados superprecoces, tem despertado o interesse dos produtores. Resultados de pesquisa (Restle et al., 1999) mostraram que animais terminados com 12-14 meses são mais eficientes na terminação que animais terminados aos 24 meses. Segundo os mesmos autores, não há diferenças acentuadas nas características de carcaça de maior importância entre as duas categorias, quando são abatidos com peso de carcaça similar, a não ser o rendimento de carcaça, que é maior nos animais mais jovens.

Quando são utilizadas raças inglesas precoces quanto à deposição de gordura, como a Aberdeen Angus, o abate aos 14 meses de animais castrados para o mercado interno deverá ser realizado com peso não superior a $400 \mathrm{~kg}$. Caso o produtor queira produzir o animal superprecoce com peso mais elevado, devem-se utilizar animais de raças mais tardias ou cruzamentos que incluam raças mais tardias, tendo em vista que depositam gordura com mais intensidade à maior idade e com maior peso (Flores, 1997). Outra alternativa, segundo Restle et al. (2000), é não castrar os animais. Esses autores verificaram que animais Braford não-castrados, abatidos aos 14 meses, apresentaram carcaças com peso de $252 \mathrm{~kg}$ e gordura de cobertura de $4 \mathrm{~mm}$; já nos animais castrados, as carcaças pesaram $222 \mathrm{~kg}$ e a gordura de cobertura foi de $6,5 \mathrm{~mm}$.

Segundo Restle et al. (1999), dois pontos são particularmente importantes quando se busca a produção do novilho superprecoce: o peso de abate e o grau de acabamento da carcaça. O peso de carcaça normalmente buscado pelos frigoríficos é acima de
$230 \mathrm{~kg}$. No entanto, carcaças com menor peso (acima de $180 \mathrm{~kg}$ ) estão sendo gradativamente aceitas pelos açougues e supermercados, que estão associando pesos mais leves de carcaça como sendo de animais mais jovens e, portanto, carne de melhor qualidade. $\mathrm{O}$ ponto crítico é a espessura de gordura de cobertura da carcaça, que deve ser acima de $3 \mathrm{~mm}$ e no máximo $6 \mathrm{~mm}$ (Restle et al., 1999). Abaixo de $3 \mathrm{~mm}$ ocorre o escurecimento da parte externa dos músculos que recobrem a carcaça, depreciando o seu valor comercial, aumenta a quebra ao resfriamento, em função da maior perda de água, e pode ocorrer o encurtamento das fibras musculares pelo frio, prejudicando a maciez da carne (Lawrie, 1981). Por outro lado, cobertura de gordura superior a $6 \mathrm{~mm}$ representa "toilette" (recorte com eliminação do excesso de gordura de cobertura) antes da pesagem da carcaça, o que acarreta maior custo operacional para o frigorífico e perda de peso da carcaça para o produtor, quando o animal é comercializado a rendimento. Os mercados americano e canadense exigem carcaças com maior espessura de gordura, necessária para que ocorra maior deposição de gordura intramuscular, ou seja, maior grau de marmorização da carne.

Maiores pesos de abate melhoram a conformação e a cobertura de gordura das carcaças (Moody et al., 1970), mas acarretam diminuição na porcentagem de traseiro (Berg \& Walters, 1983; Cruz et al., 1995; Restle et al., 1997b). O aumento da deposição de gordura na carcaça influi positivamente na maciez da carne (Vaz \& Restle, 2000). Porém, um bom grau de marmoreio pode implicar em excessiva deposição de gordura subcutânea, pélvica e recobrindo os rins e coração, que será descartada no frigorífico, reduzindo assim o rendimento de carcaça. Para evitar isto, coloca-se a pesquisa na tarefa de satisfazer as expectativas dos consumidores em encontrar carnes com menor teor de gordura, sem causar perdas em termos de maciez e palatabilidade.

A manipulação das características da carcaça pode ser realizada por intermédio de ferramentas como manejo nutricional, idade de abate e conhecimento e controle de fatores genéticos, que são elementos que influenciam grandemente a composição da carcaça e a qualidade da carne (Holton et al., 1995).

Os efeitos da variação do peso de abate sobre as características da carcaça têm sido estudados sob variadas condições de ambiente, material genético, sexo, estado sexual e idade. É de consenso geral entre os resultados obtidos que, sob um mesmo nível 
nutricional, a composição da carcaça varia em maior amplitude na proporção de gordura e menor de músculo e a porcentagem do osso permanece constante ou com pequena variação (Berg \& Walters, 1983).

Ao estudarem em novilhos das raças Aberdeen Angus e Hereford, abatidos com diferentes pesos, Dinkel et al. (1969) verificaram diferenças $(P<0,05)$ no rendimento de carcaça e no grau de marmoreio entre a progênie de touros de diferentes propriedades. Ao relacionar o peso de abate destes novilhos com o peso dos cortes produzidos, os autores encontraram a mesma relação para as duas raças, a qual foi representada por uma reta ascendente com pequeno aplainamento no centro. A tendência à linearidade foi atribuída ao fato de os animais não estarem próximos à sua maturidade fisiológica no momento do abate.

Verificam-se variações nos rendimentos de carcaça em experimentos onde os abates são realizados a partir do início do período de alimentação ou em períodos menores que 30 dias, como nos conduzidos por Zinn et al. (1970), May et al. (1992) e Schenell et al. (1997). Segundo Restle et al. (1997b), existe tendência de aumentar o rendimento de carcaça em animais de maior peso, em conseqüencia de maior deposição de gordura na carcaça. Além disso, Di Marco (1994) coloca que, ao aumentar o peso vivo, o peso relativo do conteúdo gastrintestinal, vísceras, órgãos, cabeça, couro e patas diminui, resultando em incremento no rendimento. O peso relativo dos órgãos também pode ser maior, influenciando negativamente o rendimento de carcaça, em função do rápido incremento de peso destes, quando existe ganho de peso compensatório no início do período de terminação. Matullis et al. (1987) verificaram, em vacas de descarte abatidas em diferentes períodos de alimentação, aumentos de 17,$7 ; 6,5$; e $9,1 \mathrm{~kg}$ para o peso total dos órgãos e de 1,$4 ; 0,6$; e $-0,2 \mathrm{~kg}$ para o peso do fígado nos respectivos intervalos de 0 aos 28 , 28 aos 56 e 56 aos 84 dias de confinamento.

Quando se visa à produção de carcaças mais leves em animais jovens, a precocidade na deposição de gordura é importante. Nesse caso, animais de raças precoces devem ser utilizados. As raças inglesas Hereford e Aberdeen Angus são conhecidas pela rápida deposição de gordura e pelo desenvolvimento muscular, refletindo em boa conformação da carcaça (Moletta \& Restle, 1996a,b; Restle et al., 1997b).

Tendo em vista o pequeno número de experimentos realizados em condições brasileiras avaliando os efeitos de diferentes pesos de abate sobre as características da carcaça produzida por animais abatidos precocemente, o objetivo deste experimento foi estudar o efeito de diferentes pesos de abate sobre as características quantitativas da carcaça de novilhos da raça Red Angus, confinados a partir dos oito meses de idade.

\section{Materiais e Métodos}

Foram utilizados 24 novilhos castrados da raça Aberdeen Angus, variedade Red, tomados ao acaso no mesmo rebanho. Ao início do experimento, os animais pesavam $189,1 \pm 1,78 \mathrm{~kg}$, com idade média de 8 meses.

Foram avaliadas as características de carcaça de novilhos submetidos aos seguintes pesos de abate pré-estabelecidos: 340, 370, 400 e $430 \mathrm{~kg}$.

O confinamento teve duração de sete meses, durante o qual os animais foram alimentados ad libitum com uma dieta contendo, em média, 13,13\% de proteína bruta, 2,7 Mcal de energia digestível $/ \mathrm{kg}$ de matéria seca (MS). A dieta foi composta por $56,21 \%$ de silagem de milho e $43,79 \%$ de concentrado, com base na matéria seca. O concentrado teve como ingredientes farelo de soja, casca de soja, farelo de arroz integral, sal, calcário calcítico e ionóforo (monensina sódica).

Quando o peso médio dos lotes atingiu o peso prédeterminado, os animais foram submetidos a um jejum de sólidos de 16 horas e encaminhados para o abate no frigorífico, localizado a $25 \mathrm{~km}$ do confinamento, onde foram realizadas as avaliações da carcaça após resfriamento de 24 horas em câmara fria, a $1^{\circ} \mathrm{C}$. As meias-carcaças foram avaliadas quanto à deposição muscular, à conformação e à ossificação das cartilagens, no aspecto maturidade fisiológica, segundo metodologia descrita por Müller (1987).

A medida da espessura da gordura de cobertura foi feita pela média aritmética de três mensurações na altura da $12^{\mathrm{a}}$ costela na meia-carcaça direita sobre o músculo Longissimus dorsi. No mesmo local, sobre a face exposta do músculo Longissimus dorsi, foi tomada a área deste músculo em papel vegetal e, posteriormente, a área da figura foi determinada em mesa digitalizadora, utilizando-se software Siter10. Neste lado da carcaça, também foram feitas as medidas de comprimento de carcaça, tomada do bordo anterior do osso do púbis ao bordo craneal medial da primeira costela; comprimento de perna, que corresponde à distância entre o bordo anterior 
do osso do púbis e a articulação tibio-tarsiana; espessura de coxão, medido entre a face lateral e a face medial da porção superior do coxão, medida com um compasso; comprimento de braço, medido da articulação rádio carpiana até a extremidade do olécrano; e perímetro de braço. A meia carcaça esquerda foi dividida nos cortes comerciais: serrote, que compreende a região posterior da carcaça, separado do dianteiro entre a quinta e a sexta costela e do costilhar a uma distância aproximada de $20 \mathrm{~cm}$ da coluna vertebral; dianteiro, que compreende o pescoço, paleta, braço e cinco costelas; e costilhar, que compreende a região a partir da sexta costela mais os músculos abdominais.

A maturidade fisiológica é avaliada por intermédio do estudo do grau de ossificação das cartilagens presentes nos processos espinhosos das vértebras toráxicas, lombares e entre as vértebras sacrais. A conformação é uma avaliação subjetiva da expressão muscular da carcaça, que leva em conta principalmente a cobertura muscular do corte serrote, onde estão localizados os músculos de maior valor comercial. Carcaças com melhor conformação são preferidas pelos açougues e supermercados, por produzirem músculos com melhor aparência para o consumidor, além de apresentarem menor proporção de osso e maior porção comestível (Müller, 1987).

O delineamento experimental utilizado foi o inteiramente casualizado com quatro tratamentos e seis repetições. Os dados foram submetidos à análise de regressão polinomial, utilizando-se o programa estatístico SAS (1993), seguindo o modelo estatístico abaixo:

$$
\mathrm{Y}_{i j}=\mathrm{B}_{0}+\mathrm{B}_{1} \mathrm{PA}_{\mathrm{ij}}+\mathrm{B}_{2} \mathrm{PA}^{2}{ }_{\mathrm{ij}}+\mathrm{E}_{i j}
$$

em que: $\mathrm{Y}_{i j}=$ variáveis dependentes; $\mathrm{B}_{0} ; \mathrm{B}_{1} ; \mathrm{B}_{2}=$ parâmetros da equação a serem estimados; $\mathrm{PA}_{\mathrm{ij}}=$ peso de abate na repetição j do tratamento $\mathrm{i}$; $\mathrm{E}_{i j}=$ erro experimental da observação $i j, \operatorname{NID}\left(0, \sigma^{2}\right)$.

Também foram realizadas análises de correlação simples.

\section{Resultados e Discussão}

O período de confinamento teve duração de 114, 144, 173 e 213 dias, para que os animais atingissem os pesos de abate de 340, 373, 400,6 e 433,6 kg.

Na Tabela 1 constam os valores médios referentes aos pesos de abate, de carcaça fria e o rendimento de carcaça fria.

Verifica-se na Tabela 1 que animais abatidos com $340 \mathrm{~kg}$ de peso vivo produziram carcaças com $181,56 \mathrm{~kg}$, que é o peso mínimo exigido pelos frigoríficos no sul do país para o abate de animais superprecoce para o consumo interno e com grau de acabamento mínimo desejado de $3 \mathrm{~mm}$. Os pesos de abate crescentes proporcionaram aumentos lineares nos pesos de carcaça fria, sendo que a correlação entre peso de abate e peso de carcaça foi de $0,70(\mathrm{P}=$ $0,001)$. Esta tendência foi observada por vários autores avaliando animais de sexos e idades diferentes e sob variadas dietas (Moody et al., 1970; Zinn et al., 1970; Arthaud et al., 1977; Price et al., 1980; Matullis et al., 1987; Williams et al., 1989; May et al., 1992; Van Koevering et al., 1995; Del Duca et al., 1999).

Peso de carcaça é uma característica importante, pois está associado diretamente com o valor comercial do animal. Atualmente, a forma de comercialização mais usada pelos frigoríficos do sul do Brasil é a remuneração por kg de carcaça resfriada, e não por $\mathrm{kg}$ do animal vivo. Verifica-se que os animais com peso de abate de $340 \mathrm{~kg}$ apresentaram peso de carcaça fria de $181,56 \mathrm{~kg}$, atingindo o peso mínimo $(180 \mathrm{~kg})$ para animais superprecoce exigido pelos frigoríficos do sul do país. Já os animais pesando de $430 \mathrm{~kg}$ ao abate produziram carcaças com $239,33 \mathrm{~kg}$, acima do peso em geral exigido $(230 \mathrm{~kg})$ pelos frigoríficos.

Não houve relação significativa entre o peso de abate e o rendimento de carcaça, sendo o rendimento médio para os quatro tratamentos de 53,96\%. Esse rendimento de carcaça foi similar ao relatado por Restle et al. (1999), obtido com animais Hereford superprecoce abatidos com 14 meses de idade, utilizando procedimentos de pesagens e de abate iguais aos do presente experimento.

Em experimento conduzido por Dinkel et al. (1969), em que a idade média ao abate de novilhos Aberdeen Angus foi de 16 meses com pesos de 317, 408, 499 e $590 \mathrm{~kg}$, também não foi observada diferença significativa no rendimento de carcaça. Dados obtidos por Van Koevering et al. (1995) tiveram comportamento semelhante. Novilhos cruzados (raças britânicas $\mathrm{x}$ continentais) abatidos com pesos de 472, 499, $518 \mathrm{e}$ $529 \mathrm{~kg}$ tiveram semelhantes rendimentos de carcaça. Restle et al. (1997b), ao trabalharem com novilhos da raça Charolês, não encontraram diferenças no rendimento de carcaça ao abaterem animais com 421, 461 e $495 \mathrm{~kg}$ de peso vivo.

Outros autores, no entanto, relataram incremento no rendimento de carcaça, com o aumento do peso de abate. 
Tabela 1 - Médias para peso de abate, peso de carcaça fria, rendimento de carcaça fria e maturidade fisiológica de novilhos Red Angus confinados e abatidos com diferentes pesos

Table 1 - Means for slaughter weight, carcass weight, dressing percentage and carcass maturity of Red Angus steers confined and slaughtered with different weights

\begin{tabular}{|c|c|c|c|c|c|}
\hline \multirow[b]{2}{*}{$\begin{array}{l}\text { Variável } \\
\text { Variable }\end{array}$} & \multicolumn{4}{|c|}{$\begin{array}{l}\text { Peso de abate }(\mathrm{kg}) \\
\text { Slaughter weight }(\mathrm{kg})\end{array}$} & \multirow[b]{2}{*}{$\begin{array}{l}\text { Equação de regressão } \\
\text { Regression equation }\end{array}$} \\
\hline & 340 & 370 & 400 & 430 & \\
\hline $\begin{array}{l}\text { Peso de abate, } \mathrm{kg} \\
\text { Slaughter weight, } \mathrm{kg}\end{array}$ & 340,00 & 373,00 & 400,60 & 433,60 & - \\
\hline $\begin{array}{l}\text { Peso de carcaça fria }(\mathrm{kg}) \\
\text { Cold carcass weight }(\mathrm{kg})\end{array}$ & 181,56 & 203,26 & 211,50 & 239,33 & $\hat{\mathrm{Y}}=-24,051+0,605 \mathrm{PA}^{1}$ \\
\hline $\begin{array}{l}\text { Rendimento de carcaça fria (\%) } \\
\text { Dressing percentage (\%) }\end{array}$ & 53,46 & 54,60 & 52,75 & 55,14 & $\hat{\mathrm{Y}}=53,96$ \\
\hline $\begin{array}{l}\text { Maturidade fisiológica* } \\
\text { Maturity** }\end{array}$ & 14,60 & 14,50 & 14,30 & 14,80 & $\hat{\mathrm{Y}}=14,58$ \\
\hline
\end{tabular}

$1 \mathrm{P}=0,0001 \mathrm{R}^{2}=0,49$.

* Maturidade fisiológica - varia de 1 (animal velho) até 15 (animal muito jovem).

** Maturity - range from 1 (old) until 15 (very young).

$\mathrm{PA}=$ peso de abate (Slaughter weight).

Zinn et al. (1970) verificaram maiores $(\mathrm{P}<0,05)$ rendimentos médios de carcaça de animais da raça Hereford, machos e fêmeas, variando de 52,8 a $61,7 \%$, quando confinados a partir dos 8 meses de idade e abatidos do início aos 270 dias de confinamento, a intervalos de 30 dias e pesos variando de 212 a $443 \mathrm{~kg}$ para os machos e 199 a $411 \mathrm{~kg}$ para as fêmeas. Aumentos no rendimento de carcaça e maiores escores para maturidade fisiológica frente a aumentos do peso de abate também foram relatados por Moody et al. (1970) e May et al. (1992).

A maturidade fisiológica não foi afetada pelo peso de abate, possivelmente devido à pequena diferença entre as idades de abate.

A espessura de gordura subcutânea (EGS) aumentou em $0,056 \mathrm{~mm}$ por $\mathrm{kg}$ a mais no peso de abate (Tabela 2), ajustando-se à equação $\mathrm{Y}=-15,35+$ 0,056PA. Segundo a equação de regressão, a espessura de gordura de cobertura suficiente $(3,0 \mathrm{~mm})$ teria sido alcançada aos $327 \mathrm{~kg}$, produzindo carcaças de $173 \mathrm{~kg}$. Para atingir o peso mínimo de $180 \mathrm{~kg}$, o peso de abate deveria ser de $337 \mathrm{~kg}$, o que resultaria em espessura de gordura de $3,5 \mathrm{~mm}$.

No presente experimento, observam-se valores de espessura de gordura subcutânea inferiores aos citados por autores que trabalharam com animais de raças britânicas em idades semelhantes, fornecendo dietas com maior proporção de concentrado, como no relatado por Moody et al. (1970), com novilhos Aberdeen Angus abatidos a cada 28 dias, os quais verificaram aumentos na EGS $(0,91 ; 1,29 ; 1,67$; e $1,52 \mathrm{~cm})$, mas quando expressas em $\mathrm{cm} / 45 \mathrm{~kg}$ de carcaça, o aumento do peso de abate não apresentou efeito significativo. Estabelecendo abates a cada 28 dias até os 196 dias de confinamento de novilhos Hereford x Aberdeen Angus com idade inicial de 16 meses, May et al. (1992) verificaram aumentos lineares na EGS e valores próximos aos observados no presente trabalho, variando de $3,05 \mathrm{~mm}$, aos $345 \mathrm{~kg}$ de peso vivo ao início do experimento, até $21,08 \mathrm{~mm}$, no último abate com peso vivo médio de $622 \mathrm{~kg}$. Incrementos de EGS acompanhando o aumento dos pesos de abate foram relatados em outros experimentos, mesmo com grupos genéticos diferentes e em condições de meio ambiente distintas (Barber et al., 1981b; Rouquette Jr. \& Carpenter, 1981; Van Koevering et al., 1995; Cruz et al., 1995; Restle et al., 1997b; Del Duca et al., 1999).

Animais abatidos aos 370 e $400 \mathrm{~kg}$ de peso vivo proporcionaram carcaças pesando 203,26 e 211,5 kg, respectivamente, com a mesma espessura de gordura $(6,16 \mathrm{~mm})$, próximo ao limite superior estipulado pelos frigoríficos. Por outro lado, os animais abatidos aos $430 \mathrm{~kg}$ de peso vivo produziram excessiva deposição de gordura $(9,58 \mathrm{~mm})$.

Quanto à resposta da porcentagem de cortes comerciais frente à evolução do peso de abate, notase que a variação da porcentagem de corte serrote, que é o de melhor remuneração para o frigorífico, descreve uma resposta linear decrescente. A porcentagem de dianteiro permaneceu inalterada, enquanto a proporção de costilhar em relação ao peso da carcaça aumentou, à medida que se elevou o peso 
Tabela 2 - Médias para características quantitativas e composição da carcaça de novilhos Red Angus confinados e abatidos com diferentes pesos

Table 2 - Means for quantitative traits and carcass composition of Red Angus steers confined and slaughtered with different weights

\begin{tabular}{|c|c|c|c|c|c|}
\hline \multirow[b]{2}{*}{$\begin{array}{l}\text { Variável } \\
\text { Variable }\end{array}$} & \multicolumn{4}{|c|}{$\begin{array}{l}\text { Peso de abate }(\mathrm{kg}) \\
\text { Slaughter weight }(\mathrm{kg})\end{array}$} & \multirow[b]{2}{*}{$\begin{array}{c}\text { Equação de regressão } \\
\text { Regression equation }\end{array}$} \\
\hline & 340 & 370 & 400 & 430 & \\
\hline Espessura de gordura (mm) & 3,91 & 6,16 & 6,16 & 9,58 & $\hat{\mathrm{Y}}=-15,35+0,056 \mathrm{PA}^{1}$ \\
\hline $\begin{array}{l}\text { Fat thickness, } \mathrm{mm} \\
\mathrm{EGS} / 15, \mathrm{~mm} / 15 \mathrm{~kg}\end{array}$ & 0,32 & 0,46 & 0,43 & 0,59 & $\hat{\mathrm{Y}}=-0,555+0,00262 \mathrm{PA}^{2}$ \\
\hline $\begin{array}{l}\text { Fat thickness } /{ }_{15}, \mathrm{~mm} / 15 \mathrm{~kg} \\
\text { Serrote, } \% \\
\text { Saw cut, \% }\end{array}$ & 50,55 & 50,79 & 50,16 & 48,86 & $\hat{\mathrm{Y}}=57,39-0,018 \mathrm{PA}^{3}$ \\
\hline $\begin{array}{l}\text { Dianteiro, } \% \\
\text { Fore quarter, \% }\end{array}$ & 36,66 & 36,65 & 36,35 & 37,37 & $\hat{\mathrm{Y}}=36,76$ \\
\hline $\begin{array}{l}\text { Costilhar, \% } \\
\text { Side cut, \% }\end{array}$ & 12,77 & 12,55 & 13,47 & 14,57 & $\hat{\mathrm{Y}}=5,25+0,021 \mathrm{PA}^{4}$ \\
\hline $\begin{array}{l}\text { Serrote, } \mathrm{kg} \\
\text { Saw cut, } \mathrm{kg}\end{array}$ & 91,73 & 103,26 & 106,20 & 116,66 & $\hat{\mathrm{Y}}=4,7088+0,2591 \mathrm{PA}^{5}$ \\
\hline $\begin{array}{l}\text { Dianteiro, } \mathrm{kg} \\
\text { Fore quarter, } \mathrm{kg}\end{array}$ & 66,46 & 74,60 & 78,80 & 89,66 & $\hat{\mathrm{Y}}=-15,26+0,2393 \mathrm{PA}^{6}$ \\
\hline $\begin{array}{l}\text { Costilhar, } \mathrm{kg} \\
\text { Side cut, } \mathrm{kg}\end{array}$ & 23,36 & 25,40 & 28,50 & 35,00 & $\hat{\mathrm{Y}}=-20,70+0,1266 \mathrm{PA}^{7}$ \\
\hline
\end{tabular}

${ }^{1} P=0,001 R^{2}=0,39 ;{ }^{2} P=0,012 R^{2}=0,25 ;{ }^{3} P=0,011 R^{2}=0,25 ;{ }^{4} P=0,033 R^{2}=0,19 ;{ }^{5} P=0,0004 R^{2}=0,43 ;{ }^{6} P=0,0003 R^{2}=0,46 ;{ }^{7} P=0,0001 R^{2}=0,49$. $\mathrm{PA}=$ peso de abate (Slaughter weight).

de abate, concordando com o resultado obtido por Restle et al. (1997b) e comentado por Berg \& Walters (1983), de que com o avanço da maturidade ocorre decréscimo na proporção de músculos de regiões de maior valor comercial. Já Del Duca et al. (1999), ao trabalharem com novilhos da raça Ibagé, abatidos com $380,420,460,500$ e $540 \mathrm{~kg}$ de peso vivo, notaram que a porcentagem de serrote variou desproporcionalmente aos pesos de abate, sendo que a maior porcentagem ocorreu nos animais abatidos aos $420 \mathrm{~kg}$ e a menor, aos $500 \mathrm{~kg}$.

Ao se utilizarem as equações de regressão estimadas para o peso dos cortes comerciais, em função do peso de abate, verifica-se que, para cada $30 \mathrm{~kg}$ a mais no peso de abate, ocorreu aumento de peso similar entre os cortes serrote $(7,7 \mathrm{~kg})$ e dianteiro $(7,1 \mathrm{~kg})$, sendo que o corte costilhar teve menores incrementos absolutos de peso $(3,7 \mathrm{~kg})$. Ao comparar o aumento percentual dos cortes em relação ao seu próprio peso, verifica-se que o incremento do peso de abate de 340 para $433,6 \mathrm{~kg}$ resultou em maior aumento no costilhar (50\%), seguido pelo dianteiro (35\%), com o serrote apresentando o menor incremento (27\%). Segundo Berg \& Buterfield (1976), o corte serrote contém a maioria dos músculos de alto a médio ímpeto de crescimento, localizados próximos à coluna vertebral (Psoas major, Longissimus dorsi) e aos membros posteriores (Biceps femoris, Gluteus medius, Semitendinosus, Semimenbranosus e Addutor femoris).

Aumentos na porcentagem de costilhar em carcaças com maior peso e grau de terminação podem ser atribuídos à maior deposição de gordura nesta área (Vaz, 1999). Essa constatação é evidente nos dados observados no experimento de Del Duca et al. (1999), que determinaram a relação entre a porção comestível (músculo + gordura) e os ossos para cada corte comercial, verificando maior variação no costilhar $(3,7$ e 6,1$)$, para carcaças de animais abatidos com 377 e $533 \mathrm{~kg}$ de peso vivo. No traseiro, a variação foi de 3,4 a 3,8 e no dianteiro, de 3,2 a 3,9, para os mesmos pesos. No presente trabalho, a correlação da espessura de gordura com o peso de costilhar foi de $0,65(\mathrm{P}=0,0005)$ e com a percentagem de costilhar, de 0,48 $(\mathrm{P}=0,0156)$ (Tabela 3$)$.

As características que refletem a expressão muscular da carcaça encontram-se na Tabela 4.

A área do músculo Longissimus dorsi (ALD) cresceu linearmente com o aumento do peso de abate. O maior incremento na ALD ocorreu do peso de abate de $340 \mathrm{~kg}$ para o de $370 \mathrm{~kg}$ de peso vivo. A ALD dos animais abatidos com $340 \mathrm{~kg}\left(54,14 \mathrm{~cm}^{2}\right)$ 


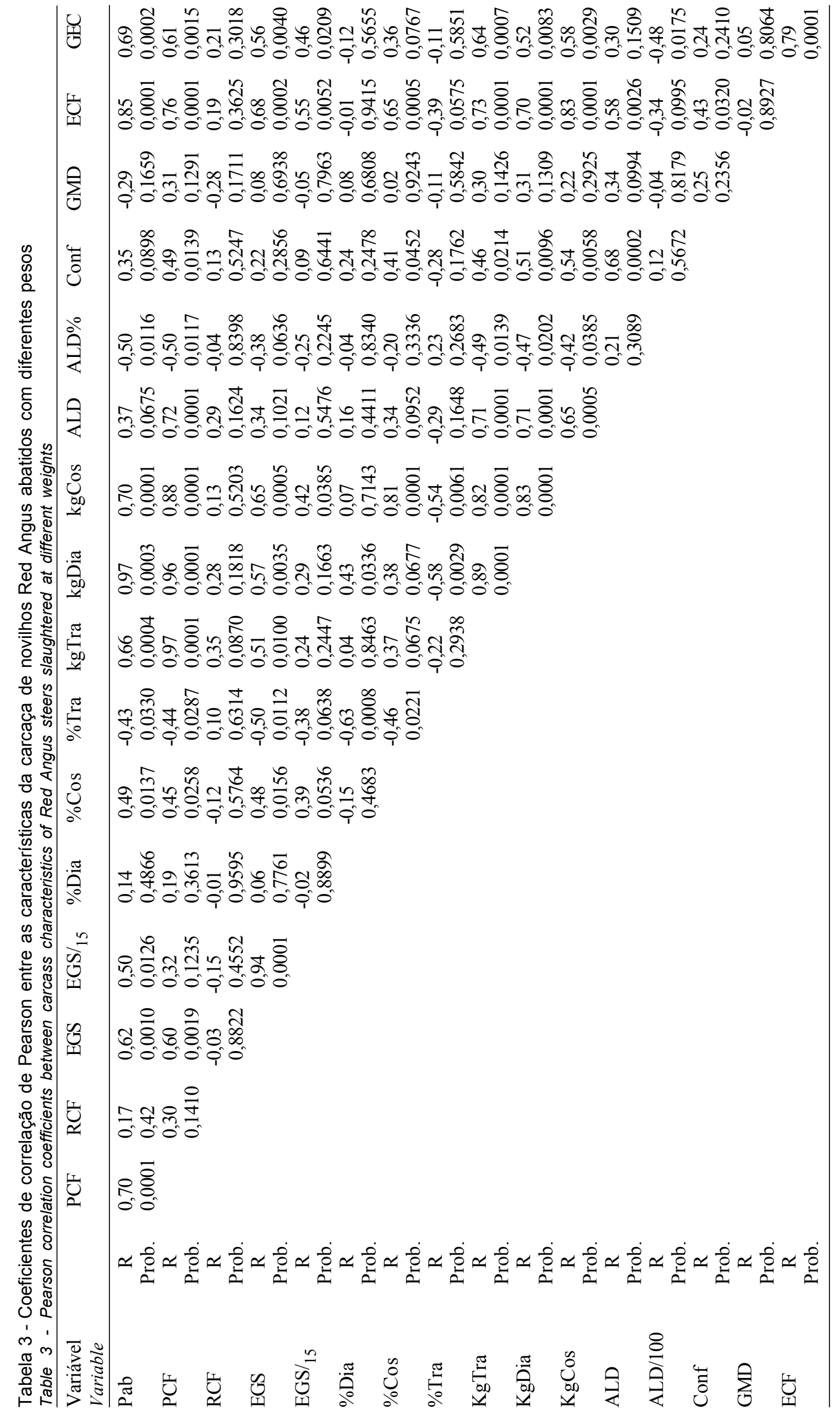




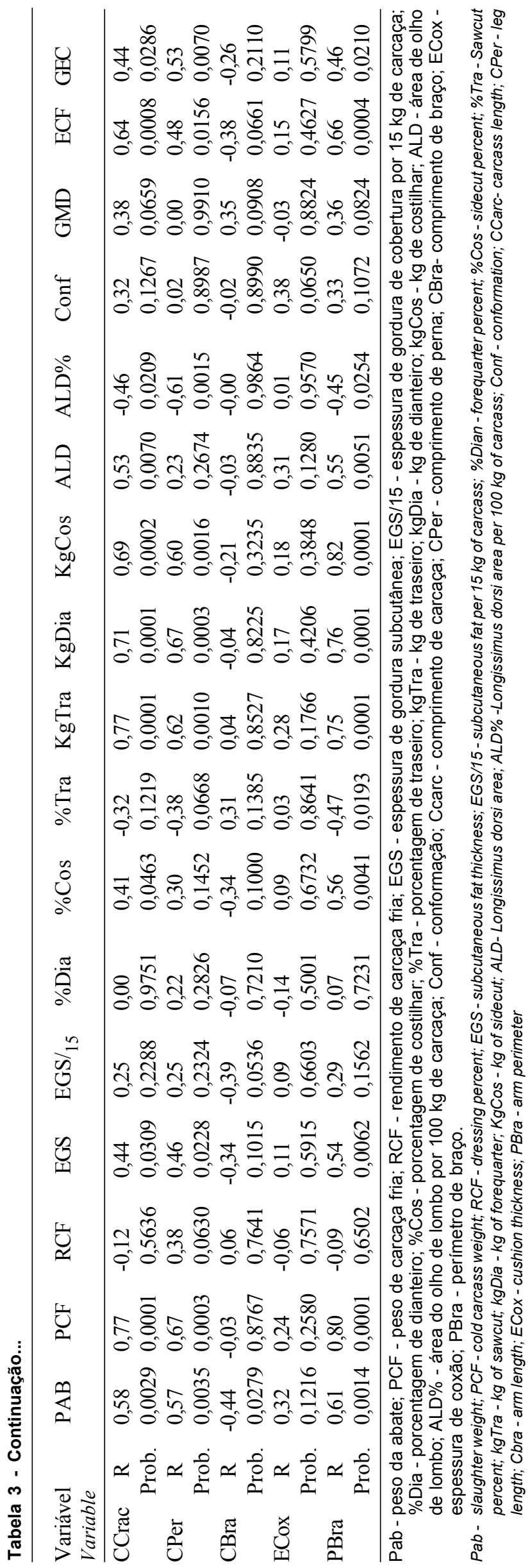

e $400 \mathrm{~kg}\left(59,94 \mathrm{~cm}^{2}\right)$ foi menor que a relatada por Dinkel et al. (1969) para os novilhos Aberdeen Angus abatidos aos $317 \mathrm{~kg}\left(62,84 \mathrm{~cm}^{2}\right)$ e $408 \mathrm{~kg}$ $\left(72,39 \mathrm{~cm}^{2}\right)$, porém com idade mais avançada. Van Koevering et al. (1995) não encontraram diferenças nos valores de área do músculo Longissimus dorsi nas carcaças produzidas por novilhos de raças de tamanho grande, abatidos aos 105, 119, 133 e 147 dias de confinamento com 82,$6 ; 83,9 ; 85,9$; e $84,8 \mathrm{~cm}^{2}$ de ALD, respectivamente.

Quando a ALD foi ajustada para $100 \mathrm{~kg}$ de carcaça, houve decréscimo linear, concordando com o observado por Moody et al. (1970), ao ajustarem os valores de ALD para $45 \mathrm{~kg}$ de carcaça. Do mesmo modo, Restle et al. (1997b) também verificaram menores ALD $/ 100 \mathrm{~kg}$ de carcaça em novilhos Charolês de peso mais elevado. Por outro lado, Galvão et al. (1991), ao avaliarem valores de ALD/100 kg de carcaça para novilhos Nelore definidos e suas cruzas com Marchigiana e Limousin, não observaram diferenças significativas entre os pesos de abate correspondentes a 90,100 e $110 \%$ do peso adulto para cada grupo genético.

A espessura de coxão, que também é uma medida de expressão muscular da carcaça, apresentou resposta quadrática frente ao aumento do peso de abate, comportamento semelhante ao observado por Restle et al. (1997b), em novilhos de uma raça mais tardia e com pesos de abate de 420 , 460 e $500 \mathrm{~kg}$, em que a espessura de coxão foi de 24,$1 ; 25,3$; e 24,7 cm, respectivamente. A correlação da espessura de coxão com peso de abate, embora positiva $(r=0,32)$, não foi significativa $(\mathrm{P}>0,1216)$. Outra medida que reflete o desenvolvimento muscular é o perímetro de braço, que aumentou linearmente frente ao aumento do peso de abate.

A conformação média das carcaças produzidas pelos animais abatidos com $340 \mathrm{~kg}$ de peso vivo foi classificada como regular+e dos demais tratamentos, como muito boa-. Embora a conformação média das carcaças tenha aumentado com o peso médio de abate, a relação não foi estatisticamente significativa. A conformação foi melhor correlacionada com peso de carcaça fria $(\mathrm{r}=0,49 ; \mathrm{P}=0,0139)$ do que com peso de abate $(r=0,35 ; P=0,0892)$. Em animais da raça Hereford, Zinn et al. (1970) relataram melhores conformações tanto para novilhos como para novilhas abatidos em intervalos de 30 dias até 270 dias de confinamento. A partir dos 150 dias, os aumentos na conformação foram menores 
para as fêmeas, provavelmente devido ao fato destas atingirem a maturidade mais cedo.

As correlações entre a conformação de carcaça e as medidas que avaliam o desenvolvimento muscular da carcaça foram de 0,68 $(\mathrm{P}=0,0002)$ para $A L D, 0,38(\mathrm{P}=0,065)$ para espessura de coxão e $0,33(\mathrm{P}=0,1072)$ para perímetro de braço. Verifica-se que a melhor associação foi com a ALD. Correlações positivas, porém inferiores, entre ALD e conformação foram relatadas por Vaz (1999).
Entre as características avaliadas que refletem o crescimento do esqueleto (Tabela 4), a regressão foi significativa para o comprimento de carcaça e comprimento de perna e braço. $\mathrm{O}$ decréscimo na medida de comprimento de braço com o maior peso de abate foi uma resposta inesperada, causada provavelmente, por diferenças existentes entre os animais na formação dos lotes no início do experimento, já que os lotes foram formados buscando equilibrar peso e estado corporal, não sendo incluídos dados de altura.

Tabela 4 - Médias para área do músculo Longissimus dorsi (ALD), área do músculo Longissimus dorsi/100 kg de carcaça, conformação e características métricas da carcaça de novilhos Red Angus confinados e abatidos com diferentes pesos

Table 4 - Means for Longissimus muscle area (LMA), Longissimus muscle area/100 kg carcass, carcass conformation and carcass metric traits of Red Angus steers confined and slaughtered at different weights

\begin{tabular}{|c|c|c|c|c|c|}
\hline \multirow[b]{2}{*}{$\begin{array}{l}\text { Variável } \\
\text { Variable }\end{array}$} & \multicolumn{4}{|c|}{$\begin{array}{l}\text { Peso de abate }(\mathrm{kg}) \\
\text { Slaughter weight }(\mathrm{kg})\end{array}$} & \multirow[t]{2}{*}{$\begin{array}{l}\text { Equação de regressão } \\
\text { Regression equation }\end{array}$} \\
\hline & 340 & 370 & 400 & 430 & \\
\hline $\begin{array}{l}\mathrm{ALD}, \mathrm{cm}^{2} \\
L M A, \mathrm{~cm}^{2}\end{array}$ & 54,1 & 61,5 & 59,9 & 63,0 & $\hat{\mathrm{Y}}=27,48+0,083 \mathrm{PA}^{1}$ \\
\hline $\begin{array}{l}\mathrm{ALD} / 100 \mathrm{~kg}, \mathrm{~cm}^{2} \\
L M A / 100 \mathrm{~kg}, \mathrm{~cm}^{2}\end{array}$ & 29,9 & 30,3 & 28,3 & 26,3 & $\hat{\mathrm{Y}}=45,14-0,0425 \mathrm{PA}^{2}$ \\
\hline $\begin{array}{l}\text { Conformação* } \\
\text { Conformation* }\end{array}$ & 9,1 & 10,3 & 10,6 & 10,6 & $\hat{\mathrm{Y}}=10,20$ \\
\hline $\begin{array}{l}\text { Perímetro Braço, } \mathrm{cm} \\
\text { Arm perimeter, } \mathrm{cm}\end{array}$ & 33,4 & 33,9 & 36,6 & 37,1 & $\hat{\mathrm{Y}}=17,32+0,046 \mathrm{PA}^{3}$ \\
\hline $\begin{array}{l}\text { Espessura de coxão, cm } \\
\text { Cushion thickness, } \mathrm{cm}\end{array}$ & 21,6 & 22,1 & 24,3 & 22,1 & $\hat{\mathrm{Y}}=-90,3+0,57 \mathrm{PA}-0,0007 \mathrm{PA}^{24}$ \\
\hline $\begin{array}{l}\text { Comprimento de carcaça, } \mathrm{cm} \\
\text { Carcass length, } \mathrm{cm}\end{array}$ & 113,8 & 116,6 & 121,0 & 120,8 & $\hat{\mathrm{Y}}=85,48+0,084 \mathrm{PA}^{5}$ \\
\hline $\begin{array}{l}\text { Comprimento perna, } \mathrm{cm} \\
\text { Leg length, } \mathrm{cm}\end{array}$ & 65,5 & 63,0 & 64,4 & 71,2 & $\hat{\mathrm{Y}}=424,9-1,94 \mathrm{PA}+0,0026 \mathrm{PA}^{26}$ \\
\hline $\begin{array}{l}\text { Comprimento braço, } \mathrm{cm} \\
\text { Arm length, } \mathrm{cm}\end{array}$ & 35,5 & 36,6 & 35,5 & 33,4 & $\hat{\mathrm{Y}}=-88+0,67 \mathrm{PA}-0,0009 \mathrm{PA}^{27}$ \\
\hline
\end{tabular}

${ }_{1} P=0,067 R^{2}=0,14 ;{ }^{2} P=0,016 R^{2}=0,25 ;{ }^{3} P=0,029 R^{2}=0,33 ;{ }^{4} P=0,0001 R^{2}=0,74 ;{ }^{5} P=0,017 R^{2}=0,39 ; 6 P=0,0014 R^{2}=0,37 ;{ }^{7} P=0,0052 R^{2}=0,38$.

* Conformação: 9 = regular mais, $10=$ boa menos, $11=$ boa.

* Conformation: 9 = regular,$+ 10=$ good,$- 11=$ good

$\mathrm{PA}=$ peso de abate (Slaughter weight).

\section{Conclusões}

A variação do peso de abate de novilhos superprecoce Aberdeen Angus entre 340 e 433,6 kg não alterou o rendimento de carcaça fria nem a conformação de carcaça.

O corte serrote aumentou em peso com o incremento do peso de abate e decresceu quando expresso como porcentagem do peso de carcaça. $\mathrm{O}$ corte que teve o maior incremento percentual frente ao aumento do peso de abate foi o costilhar, acompanhando o aumento na espessura de gordura subcutânea, ambos aumentando linearmente em relação ao peso de abate.

Com peso de abate de $337 \mathrm{~kg}$ foi atingido o peso de carcaça mínimo e espessura de gordura suficiente exigidos pelos frigoríficos para novilhos superprecoce.

Quando se abatem novilhos Aberdeen Angus superprecoces para o consumo do mercado interno, o 
peso de abate não deve ser superior aos $400 \mathrm{~kg}$, para não exceder os $6 \mathrm{~mm}$ de gordura de cobertura na carcaça.

\section{Literatura Citada}

ARTHAUD, V.H.; MANDIGO, R.W.; KOCH, R.N. et al. Carcass composition, quality and palatability attributes of bulls and steers fed different energy levels and killed at four ages. Journal of Animal Science, v.44, p.53-64, 1977.

BARBER, K.A.; WILSON, L.L.; ZIEGLER, J.H. et al. Charolais and Angus steers slaughtered at equal percentages of mature cow weight. II. Empty body composition, energetic efficiency and comparison of compositionally similar body weights. Journal of Animal Science, v.53, p.898-906, 1981a.

BARBER, K.A.; WILSON, L.L.; ZIEGLER, J.H. et al. Charolais and Angus steers slaughtered at equal percentages of mature cow weight. I. Effects of slaughter weight and diet energy density on carcass traits. Journal of Animal Science, v.53, n.2, p.218-231, 1981 b.

BERG, R.T.; BUTTERFIELD, R.M. New concepts of cattle growth. Sydney: Sydney University Press, 1976. 240p.

BERG,R.T.;WALTERS,L.E. Themeat animal: changes and chalenges. Journal of Animal Science. v.57, S2, p.133-146, 1983.

CRUZ, G.M.; TULLIO, R.R.; ESTEVES, S.N. et al. Peso ótimo de abate de machos cruzados para produção do bovino jovem. I. Desempenho em confinamento e características de carcaça. In: REUNIÃO ANUAL DA SOCIEDADE BRASILEIRA DE ZOOTECNIA, 32., 1995, Brasília. Anais... Viçosa: Sociedade Brasileira de Zootecnia, 1995. p.223.

DEL DUCA, L.O.A.; MORAES, C.O.C.; SALOMONI, E.; et al. Efeito do peso de abate nas características quantitativas da carcaça de novilhos Ibagé. In: REUNIÃO ANUAL DA SOCIEDADE BRASILEIRA DE ZOOTECNIA, 1999, 36., Porto Alegre. Anais...Viçosa: Sociedade Brasileira de Zootecnia, 1999. p.357.

DI MARCO, O.N. Crescimiento y respuesta animal. Buenos Aires: Associación Argentina de Producción Animal, 1994. 129p.

DINKEL, C.A.; BUSCH, D.A.; SCHAFER, D.E. et al. Changes in composition of beef carcasses with increasing animal weight. Journal of Animal Science, v.28, p.316-323, 1969.

FLORES, J.L.C. Desempenho em confinamento de terneiros inteiros de diferentes grupos genéticos na fase do desmame ao abate aos 14 meses. Santa Maria: Universidade Federal de Santa Maria, 1997. 136p. Dissertação (Mestrado em Zootecnia) - Universidade Federal de Santa Maria, 1997.

GALVÃO, J.G.; FONTES, C.A.A.; PIRES, C.C. et al. Características e composição física da carcaça de bovinos não castrados, abatidos em três estágios de maturidade (estudo II) de três grupos raciais. Revista da Sociedade Brasileira de Zootecnia, v.20, n., p.502-512, 1991.

HOLTON, P.; WILLIAMS, S.E.; BAKER, J.F.; FRINGLE, T.D. et al. Comparison of palatability and carcass traits of steers from large and medium frame Angus and Limousin sires fed for 120, 140 and 160 days. Animal and Dairy Science, Annual Report, 1995. p.75-80.

LAWRIE, R. Developments in meat science. London: Elsevier Applied Science, 1981, v.5.

MATULLIS, R.J.; McKEITH, F.K.; FAULKNER, D.B. et al. Growth and carcass characteristics of cull cows after different times-onfeed. Journal of Animal Science, v.65, p.669-674, 1987.

MAY, S.G.; DOLEZAL, H.G.; GILL, D.R. et al. Effects of days fed, carcass grade traits, and subcutaneous fat removal on postmortem muscle characteristics and beef palatability. Journal of Animal Science, v.70, p.444-453, 1992.

MOLETTA, J.L.; RESTLE, J. Características de carcaça de novilhos de diferentes grupos genéticos terminados em confinamento. Revista Brasileira de Zootecnia, v.25, n.5, p.876-888, 1996 a.
MOLETTA, J.L.; RESTLE, J. Influência do grupo genético sobre características qualitativas da carne de novilhos. Revista Brasileira de Zootecnia, v.25, n.5, p.866-875, 1996 b.

MOODY, W.G.; LITTLE Jr.; THRIFT, E.A. et al. Influence of length of a high roughage ration on quantitative and qualitative characteristics of beef. Journal of Animal Science, v.31, p.866-873, 1970.

MÜLLER, L. Normas para avaliação de carcaças e concurso de carcaças de novilhos. 2 .ed. Santa Maria: Universidade Federal de Santa Maria, 1987. 31p.

PRICE, M.A.; JONES, S.D.M.; MATHISON, G.W. et al. The effects of increasing dietary roughage level and slaughter weight on the feedlot performance and carcass characteristics of bulls and steers. Canadian Journal of Animal Science, v.60, p.345-358, 1980.

RESTLE, J. KEPLIN, L.A.S; VAZ, F.N. et al. Desempenho em confinamento de novilhos Charolês abatidos com diferentes pesos. Pesquisa Agropecuária Brasileira, v.32, n.8, p.857860, 1997a.

RESTLE, J. KEPLIN, L.A.S; VAZ, F.N. et al. Características quantitativas da carcaça de novilhos Charolês, abatidos com diferentes pesos. Pesquisa Agropecuária Brasileira, v.32, n.8, p.851-856, 1997b.

RESTLE, J.; BRONDANI, I.L.; BERNARDES, R.A.C. O novilho superprecoce. In: RESTLE, J. (Ed.) Confinamento, pastagens e suplementação para produção de bovinos de corte. Santa Maria: Universidade Federal de Santa Maria, 1999. p.191-214.

RESTLE, J.; ALVES FILHO, D.C.; NEUMANN, M. Eficiência na terminação de bovinos de corte. In: RESTLE, J. (Ed.) Eficiência na produção de bovinos de corte. Santa Maria: Universidade Federal de Santa Maria, 2000. p.277-303.

ROUQUETTE Jr., F.M.; CARPENTER, Z.L. Carcass characteristics of weanling calves grazed at three levels of forage availability. Journal of Animal Science, v.53, n.892-897, 1981.

SAS INSTITUTE. SAS/STAT user's guide: statistics. 4.ed. Version 6. Cary: 1993. 943p.

SCHNELL, T.D.; BELK, K.E.; TATUM, J.D. et al. Performance, carcass, and palatability traits for cull cows fed high-energy concentrate diets for 0, 14, 28, 42 or 56 days. Journal of Animal Science, v.75, p.1195-1202, 1997.

Van KOEVERING, M.T.; GILL, D.R.; OWENS, F.N. et al. Effects of time on feed on performance of feedlot steers, carcass characteristics, and tenderness and composition of Longissimus muscles. Journal of Animal Science, v.73, p.21-28, 1995.

VAZ, F.N. Cruzamento alternado das raças Charolês e Nelore: características da carcaça e da carne de novilhos abatidos aos dois anos. Santa Maria: Universidade Federal de Santa Maria, 1999. 58p. Dissertação (Mestrado em Zootecnia) - Universidade Federal de Santa Maria, 1999.

VAZ, F.N.; RESTLE, J. Aspectos quantitativos da carcaça e da carne de machos Hereford, inteiros ou castrados, abatidos aos quatorze meses. Revista da Sociedade Brasileira de Zootecnia, v.29, n.6, p.1894-1901, 2000.

WILLIAMS, S.E.; TATUM, J.D.; STATON, T.L. The effects of muscle thickness and time on feed on hot fat trim yields, carcass characteristics and boneless subprimal yelds. Journal of Animal Science, v.67, p.2669-2676, 1989.

ZINN, D.W.; DURHAM, R.M.; HEDRICK, H.B. Feedlot and carcass grade characteristics of steers and heifers as influenced by days on feed. Journal of Animal Science, v.31, p.302-306, 1970 . 